\title{
Correction to: Zinc micronutrient-loaded carboxymethyl tamarind kernel gum-based superabsorbent hydrogels: controlled release and kinetics studies for agricultural applications
}

\author{
Khushbu $^{1}$ - Sudhir G. Warkar ${ }^{1}$ - Nandkishore Thombare ${ }^{2}$
}

Published online: 19 July 2021

๑) Springer-Verlag GmbH Germany, part of Springer Nature 2021

\section{Colloid and Polymer Science https://doi.org/ 10.1007/s00396-021-04831-8}

The original version of this article unfortunately contained an error. The corresponding author did not notice that Publisher's Note Springer Nature remains neutral with regard to one of the co-authors "Khatri Khushbu" was incorrectly presented. The desired name is "Khushbu". Given in this article is the corrected author name.

The original article has been corrected.

The original article can be found online at https://doi.org/10.1007/ s00396-021-04831-8.

Sudhir G. Warkar

sudhirwarkar@gmail.com

1 Department of Applied Chemistry, Delhi Technological

University, Delhi 110042, India

2 Processing and Product Development Division,

ICAR- Indian Institute of Natural Resins and Gums,

Namkum, Ranchi 834010, India 